\title{
Short communication: Feeding method affects the feeding behavior of growing dairy heifers
}

\author{
T. J. DeVries ${ }^{\star 1}$ and M. A. G. von Keyserlingk† \\ *Department of Animal and Poultry Science, University of Guelph, Kemptville Campus, Kemptville, Ontario, K0G 1J0, Canada \\ †Animal Welfare Program, The University of British Columbia, Vancouver, British Columbia, V6T 1Z4, Canada
}

\begin{abstract}
There is limited information available on what is the most appropriate feeding method for growing dairy heifers. The objective of this study was to determine the effect of feeding method on the feeding behavior and diet selection of growing dairy heifers. Six prepubescent Holstein heifers $(158.2 \pm 4.0 \mathrm{~d}$ old, weighing $168.2 \pm$ $15.7 \mathrm{~kg}$ ), fed once per day for $1.0 \mathrm{~kg} / \mathrm{d}$ of growth, were subjected to each of 3 treatments in 3 successive 7 -d treatment periods using a replicated $3 \times 3$ Latin square design. Treatments consisted of feeding $2.02 \mathrm{~kg} / \mathrm{d}$ dry matter of grain concentrate and ad libitum chopped grass hay as: 1) choice (grain concentrate and hay in separate feed bins), 2) top-dressed ration (grain concentrate placed on top of the hay in one feed bin), and 3) total mixed ration (TMR, grain concentrate mixed with hay in one feed bin). Dry matter intake (DMI) and feeding behavior were monitored for $7 \mathrm{~d}$ for each animal on each treatment, and feed sorting was monitored for the last $3 \mathrm{~d}$ of each treatment period. The provision of grain concentrate and hay in either a choice or top-dressed situation resulted in young dairy heifers rapidly consuming the grain concentrate portion of their ration in very few, large meals before consuming the hay portion of their ration. The provision of the 2 ration ingredients as a TMR increased the distribution of DMI over the day and reduced the amount of sorting (against long forage particles, and for short grain concentrate particles) by heifers. These results suggest that the provision of a TMR to growing dairy heifers, as opposed to feeding concentrate and hay as either a choice or top-dressed, promotes a more balanced intake of nutrients across the day.
\end{abstract}

Key words: heifer, component feeding, TMR, sorting

Providing the ration as a TMR is now common practice on most commercial dairy farms for nearly all

Received April 29, 2008.

Accepted November 2, 2008.

${ }^{1}$ Corresponding author: tdevries@kemptvillec.uoguelph.ca classes of animals over 6 mo of age. This practice is supposed to decrease sorting of the individual ration components by dairy cattle (Coppock et al., 1981). However, feeding management practices employed for the young weaned dairy heifer continue to be variable. Although the typical diet consists of grain concentrate and roughage (Murphy, 2004), the concentrate is provided in different ways, typically either separate from or on top of the roughage (top dressing).

Østergaard and Grohn (2000) reported that feeding concentrates separately from forage was associated with increased risk of metabolic disorders in adult dairy cattle. Maekawa et al. (2002) reported that feeding the forage and concentrate separately resulted in cows consuming a higher proportion of concentrate than intended, increasing the risk of ruminal acidosis (Beauchemin et al., 2002). Alternatively, feeding a TMR should promote a more uniform feed consumption, reducing the risk of acidosis (Hernandez-Urdaneta et al., 1976). Borland and Kesler (1979) suggested that the use of TMR for young heifers may result in a better balance of nutrient intake by avoiding individual preferences for forage or concentrate. To date, there is no data available that describes how feeding methods influence the feeding behavior of prepubertal dairy heifers. It could be hypothesized that providing the concentrate and hay together in the form of a TMR would reduce feeding patterns that result in a few large meals of concentrate. Given that dairy cattle, young and mature, sort their TMR for grain concentrate and against long forage particles (Leonardi and Armentano, 2003; Greter et al., 2008), it could also be hypothesized that heifers might actively sort a grain concentrate/ hay mixture in an attempt to consume the concentrate before the hay component. Thus, the objective of this study was to determine the effect of feeding method on the feeding behavior and diet selection of growing dairy heifers.

Six Holstein heifers $158.2 \pm 4.0$ (mean \pm SD) days old, weighing $168.2 \pm 15.7 \mathrm{~kg}$, and $103.7 \pm 3.2 \mathrm{~cm}$ high at the withers at the beginning of the data collection period were used. Animals gained, on average, $1.19 \pm 0.4 \mathrm{~kg} / \mathrm{d}$ and grew $0.10 \pm 0.14 \mathrm{~cm} / \mathrm{d}$ during the 
Table 1. Chemical composition and particle size distribution of the dietary ingredients and ration fed to growing dairy heifers

\begin{tabular}{|c|c|c|c|}
\hline Item & Concentrate $^{1}$ & Grass hay $^{2}$ & Ration $^{3}$ \\
\hline \multicolumn{4}{|c|}{ Chemical composition $^{4}$} \\
\hline DM, \% & 89.2 & 83.8 & 85.7 \\
\hline $\mathrm{OM}, \%$ of $\mathrm{DM}$ & 93.2 & 90.4 & 91.3 \\
\hline $\mathrm{CP}, \%$ of $\mathrm{DM}$ & 18.9 & 16.7 & 18.3 \\
\hline $\mathrm{ADF}, \%$ of $\mathrm{DM}$ & 11.9 & 33.4 & 22.8 \\
\hline NDF, $\%$ of DM & 22.3 & 53.8 & 39.0 \\
\hline NFC, $\%$ of DM & 18.3 & 48.5 & 31.5 \\
\hline \multicolumn{4}{|c|}{ Particle size ${ }^{5} \%$ of DM retained on screen } \\
\hline Long & 0.0 & 59.5 & 30.8 \\
\hline Medium & 7.7 & 18.3 & 17.0 \\
\hline Short & 91.1 & 17.1 & 48.0 \\
\hline Fine & 1.2 & 5.1 & 4.2 \\
\hline
\end{tabular}

${ }^{1}$ Textured calf grower supplied by Unifeed Ltd. (Chilliwack, BC, Canada), containing (on as-is basis): $15.0 \%$ flatted corn, $14.0 \%$ canola meal, $12.9 \%$ ground wheat, $11.6 \%$ soymeal, $10.2 \%$ mixed grains, $9.0 \%$ flatted oats, $8.4 \%$ millrun, $7.0 \%$ flatted barley, $4.8 \%$ molasses, $2.3 \%$ calcium carbonate, $1.6 \%$ ground barley, $1.3 \%$ salt, $0.7 \%$ dicalcium phosphate, $0.6 \%$ ground alfalfa pellets, $0.3 \%$ ground corn, $0.2 \%$ trace mineral/vitamin premix, $0.07 \%$ lasolacid sodium (Bovatec).

${ }^{2}$ Chopped using a TMR mixing wagon.

${ }^{3}$ Containing, on a DM basis, $38.1 \%$ concentrate and $61.9 \%$ grass hay (based on average consumption of $3.28 \mathrm{~kg}$ of grass hay with fixed $2.02-\mathrm{kg}$ amount of concentrate).

${ }^{4}$ Values were obtained from chemical analysis of feed samples; OM $=100-\%$ ash; NFC $=100-(\% \mathrm{CP}+$ $\% \mathrm{NDF}+\%$ fat $+\%$ ash $)$.

${ }^{5}$ Particle size determined by Penn State Particle Separator, which has a 19-mm screen (long), 8-mm screen (medium), 1.18-mm screen (short), and a pan (fine).

study period. Animals were housed at The University of British Columbia Dairy Education and Research Centre (Agassiz, BC, Canada) and were managed according to the guidelines set by the Canadian Council on Animal Care (1993). Heifers were housed in a pen that consisted of 2 sawdust bedded-pack areas (each 4.6 $\times 5.0 \mathrm{~m}$; width $\times$ depth $)$ and a standing alley $(9.2 \times$ $3.05 \mathrm{~m}$ ), which divided the pack from the feeding area. Feed was provided using 6 roughage intake control feed bins (Insentec BV, Marknesse, the Netherlands). Each heifer was assigned and trained to eat exclusively from 2 adjacent feed bins. Orts were removed from the feed bins each day beginning at $0730 \mathrm{~h}$, immediately before the once-per-day delivery of fresh feed at $0800 \mathrm{~h}$.

Heifers were split into 2 groups that were balanced by age, weight, and size. Within each group, each heifer was tested on 3 treatments using a $3 \times 3$ Latin square design. Treatments were: 1$)$ choice ration $(2.02 \mathrm{~kg} / \mathrm{d}$ DM concentrate in one feed bin, ad libitum chopped grass hay in the other feed bin), 2) top-dressed ration (2.02 $\mathrm{kg} / \mathrm{d}$ concentrate placed on top of ad libitum chopped grass hay in one feed bin) and, 3) TMR (2.02 kg concentrate hand mixed with ad libitum chopped grass hay in one feed bin). The diet was formulated according to the NRC (2001) nutrient requirement recommendations for a $150-\mathrm{kg}$ nonbred Holstein heifer growing at $1.0 \mathrm{~kg} / \mathrm{d}$ (Table 1). Although each heifer had been trained to use 2 bins, in the case of the top-dressed and TMR rations, feed was only provided in 1 of the 2 feed bins. During the application of these treatments, the second, empty bin was electronically programmed to remain closed to prevent access by the heifers. Given the fixed amount of concentrate, the amount of hay offered to each animal was adjusted daily to target $10 \%$ orts.

Each group of animals was housed together for 7 d before exposure to the experimental diets to allow for social adaptation and to facilitate training to their specific feed bins. During this period heifers were fed according to the standard practice employed at the University of British Columbia Dairy Education and Research Centre of providing the $2.02 \mathrm{~kg}$ of concentrate (split between each heifer's 2 feed bins) top-dressed on ad libitum chopped hay. Initially, the first 3 heifers were exposed to each treatment in 3 successive 7 -d treatment periods in a Latin square design. A second replication, consisting of the same 1 week adaptation/training period and 3-wk treatment exposure period, using the other group of 3 heifers took place immediately following the completion of the first replication.

Feeding behavior and individual feed intake was monitored continuously for all experimental animals (Insentec BV). From the recorded data, the duration, amount of feed consumed, and feed consumption rate for each visit, daily DMI $(\mathrm{kg} / \mathrm{d})$, daily time spent feeding $(\mathrm{min} / \mathrm{d})$, and average feeding rate $(\mathrm{kg} / \mathrm{min})$ for each heifer were calculated. Visits to the feed intake system were separated into meals using an individual meal criterion (DeVries et al., 2003), and averaged $17.9 \pm 7.2$ 
(mean $\pm \mathrm{SD}$ ) min. Using these criteria, meal frequency, duration, and size were calculated.

Representative samples for particle size separation of the offered feed (concentrate, hay, concentrate/ hay ration) were taken on $\mathrm{d} 5,6$, and 7 of each treatment period. Duplicate samples of these were taken on d 5 during each of the treatment periods for DM and chemical analysis. Orts samples for particle size separation to determine sorting for animals on the top dressed and TMR treatments were taken just before cleaning the feed bins out at the end of $\mathrm{d} 5,6$, and 7 during each treatment period. All samples were immediately frozen until further analyses. Samples for particle size separation were separated using the 3 -screen Penn State Particle Separator (PSPS; Kononoff et al., 2003). After separation, the DM of each separated fraction was determined by oven drying at $55^{\circ} \mathrm{C}$ for 48 h. Samples taken for DM and chemical analysis were oven-dried at $55^{\circ} \mathrm{C}$ for $48 \mathrm{~h}$ and then ground to pass through a 1-mm screen (Brinkmann Mill, Brinkmann Instruments Co., Westbury, NY). Samples were then pooled by replication and sent to Cumberland Valley Analytical Services Inc. (Maugansville, MD) for analysis of DM $\left(135^{\circ} \mathrm{C}\right.$; AOAC, 2000; method 930.15), ash $\left(535^{\circ} \mathrm{C}\right.$; AOAC, 2000 ; method 942.05), ADF (AOAC, 2000; method 973.18), NDF with heat-stable $\alpha$-amylase and sodium sulfite (Van Soest et al., 1991), fat (AOAC, 1990; method 920.39), and CP $(\mathrm{N} \times 6.25$; AOAC 2000; method 990.03; Leco FP-528 Nitrogen Analyzer, Leco, St. Joseph, MI).

Sorting was calculated as the actual DMI of each fraction of the PSPS expressed as a percentage of the predicted DMI of that fraction (Leonardi and Armentano, 2003). Predicted intake of each individual fraction was calculated as the product of the total DMI multiplied by the DM percentage of that fraction in the feed provided to the heifer. Values equal to $100 \%$ indicate no sorting, $<100 \%$ indicate selective refusals (sorting against), and $>100 \%$ indicate preferential consumption (sorting for). To test whether sorting occurred on the top-dressed and TMR rations, data for each fraction of the PSPS was averaged across the last $3 \mathrm{~d}$ of each treatment period for each heifer and tested for a difference from 100 using $t$-tests. Because there was no adaptation between different treatment periods, a preliminary analysis of the effect of day within treatment period was conducted on the DMI and feeding behavior data. This analysis revealed no day effect and, therefore, DMI and feeding behavior data were averaged across the $7 \mathrm{~d}$ of each treatment period for each heifer. For the choice ration, DMI and feeding behavior data were also summarized for each feed component. All data were analyzed using the MIXED procedure of SAS (SAS Institute, 2003). The model included the fixed effect of treatment, the random effects of period and square, and the residual error. The Tukey-Kramer adjustment was used in testing for differences between individual treatments. Data for DMI, feeding time, and feeding rate were also summarized on an hourly basis for each animal on each treatment. For the choice ration, these data were also summarized on an hourly basis for each feed component. Differences among treatments in the distribution of these variables over a 24 -h period were analyzed using the MIXED procedure of SAS treating hour as a repeated measure. The model included the fixed effects of hour, treatment, and hour by treatment interaction, the random effects of period and square, and the residual error. Heifer within square was included in the model as the subject of the repeated statement. Compound symmetry was selected as the covariance structure on the basis of best fit according to Schwarz's Bayesian information criterion. All values reported are least squares means. Significance was declared at $P \leq$ 0.05 and trends reported if $0.05<P \leq 0.15$.

Across treatments, heifers consumed over $1.0 \mathrm{~kg} / \mathrm{d}$ more DM (Table 2) than predicted based on the NRC (2001) requirements. Given that the amount of concentrate was fixed at $2.02 \mathrm{~kg} / \mathrm{d}$, this increased DMI resulted from higher intakes of forage than initially predicted. As such, their nutrient intake supported a higher rate of gain $(1.2 \mathrm{~kg} / \mathrm{d})$, as observed in the study, than that initially predicted.

There was no difference in DMI between any of the treatments (Table 2). Maekawa et al. (2002) also found that component-fed lactating cows had similar DMI compared with cows fed a TMR. The advantage of feeding dairy cattle a TMR over component feeding may in fact not lie in improved DMI, but rather in forcing cattle to ingest a balanced diet at every meal, resulting in stable rumen function and ingesta flow (Coppock et al., 1981). To help determine what heifers were actually consuming, we analyzed their feed sorting behavior (Table 3). The sorting for short particles on both the top-dressed and TMR treatments was expected, given that the short fraction was largely made up of grain concentrate. The greater degree of sorting for short particles when fed the top-dressed ration provides further evidence that heifers were able to consume a large proportion of the concentrate apart from the hay. Interestingly, when provided the top-dressed ration, heifers sorted against long particles to a great extent but did not sort against these when provided the TMR. This lack of sorting against long particles on the TMR is surprising given that dairy cattle, young and mature, typically sort against long forage particles (Leonardi and Armentano, 2003; Greter et al., 2008). The extent of sorting against long particles is typically similar, regardless of nutrition or management strategy used. 
Table 2. Intake and feeding behavior measures from growing dairy heifers on the dietary treatments ${ }^{1}$

\begin{tabular}{|c|c|c|c|c|c|c|c|c|}
\hline Item & \multicolumn{3}{|c|}{ Dietary treatment ${ }^{2}$} & $\mathrm{SE}$ & \multicolumn{4}{|c|}{$P$-value } \\
\hline Feeding time, $\min / \mathrm{d}$ & 140.65 & 168.79 & 188.40 & 20.88 & 0.001 & 0.02 & 0.001 & 0.1 \\
\hline Feeding rate, $\mathrm{kg} / \mathrm{min}$ & 0.057 & 0.042 & 0.045 & 0.007 & 0.02 & 0.02 & 0.05 & 0.8 \\
\hline Meal frequency, meals/d & 11.07 & 9.75 & 9.62 & 1.04 & 0.1 & 0.17 & 0.13 & 0.9 \\
\hline
\end{tabular}

${ }^{1}$ Data are averaged over $7 \mathrm{~d}$ for 6 heifers on each treatment.

${ }^{2} 2.02 \mathrm{~kg}$ concentrate fed separately from (choice ration), top-dressed on (top dressed), or mixed with (TMR) grass hay fed ad libitum.

${ }^{3}$ Main effect of dietary treatment.

${ }^{4}$ Statistical contrasts of individual dietary treatments.

Heifers tended to discriminate for short particles and discriminate against the fine particles on the TMR. The fine particle fraction consisted of primarily fine forage particles and, given the small percentage of the total ration that this represented, was likely not biologically meaningful.

The analysis of the diurnal pattern of DMI showed a treatment by hour interaction $(\mathrm{SE}=0.04, P<0.001$; Figure 1a). This interaction reflects the reduced DMI of the heifers on the TMR ration during the period of peak feeding activity and their consistently higher DMI during the rest of the daylight hours compared with the other 2 treatments. This change in feeding behavior pattern, along with the sorting data, suggests that heifers consuming the TMR were unable to discriminate as easily and thus consumed a ration closer to that initially designed for them, resulting in a more balanced intake of nutrients over the course of the day. These findings support the benefits that were outlined by Coppock et al. (1981) on feeding TMR to adult dairy cattle. Interestingly, DMI was similar during the first $2 \mathrm{~h}$ following feed delivery on the choice and top-dressed diets. From the consumption pattern data, it is clear that heifers preferentially consumed the grain concentrate before consuming the hay on the choice and top-dressed treatments. A similar result was reported by Quigley et al. (1992) who found that growing dairy heifers consumed $3.7 \mathrm{~kg}$ of concentrate within a few hours after feeding, before consuming their hay. In the present study, given these consumption patterns and that a fixed amount of concentrate was fed to the heifers, the proportion of concentrate and hay consumed would have been similar between these treatments.

We noted a feed component by hour interaction $(P$ $<0.001)$ for the diurnal analysis of DMI on the choice ration $(\mathrm{SE}=0.03$; Figure 2a), feeding time $(\mathrm{SE}=1.22$; Figure $2 \mathrm{~b})$, and feeding rate $(\mathrm{SE}=0.007$; Figure 2c). These interactions reflect that the DMI, feeding time, and feeding rate of the concentrate were higher than that of hay during the time period immediately following feed delivery. However, for the remainder of the day DMI, feeding time, and feeding rate of hay were consistently higher than that observed for the concentrate portion of the ration. Maekawa et al. (2002) found that feeding forage and concentrate separately resulted in dairy cows consuming a higher proportion of concentrate than intended. In the present study, this was not possible given the fixed amount of concentrate fed. However, given the consumption patterns of the heifers on the choice treatment, and to a lesser extent on the top-dressed treatment, it is possible that under certain conditions (e.g., high competition at the feed bunk) heifers may consume more concentrate than intended, even in situations where a fixed amount of concentrate per animal is provided. González et al. (2008) reported that variability in eating time and final BW tended to

Table 3. Effect of dietary treatments on the sorting (\%) of long, medium, short, and fine particles by growing dairy heifers ${ }^{1,2}$

\begin{tabular}{|c|c|c|c|c|}
\hline \multirow[b]{2}{*}{ Particles $^{4}$} & \multicolumn{2}{|c|}{ Dietary treatment ${ }^{3}$} & \multirow[b]{2}{*}{$\mathrm{SE}$} & \multirow[b]{2}{*}{$P$-value } \\
\hline & Top dressed & TMR & & \\
\hline Long & $89.7^{*}$ & 97.6 & 3.6 & 0.046 \\
\hline Medium & $96.0 \dagger$ & 97.5 & 1.6 & 0.44 \\
\hline Short & $107.2^{* *}$ & $102.8 \dagger$ & 1.7 & 0.027 \\
\hline Fine & $93.2 \dagger$ & $90.5^{*}$ & 2.8 & 0.52 \\
\hline
\end{tabular}

${ }^{1}$ Sorting $\%=100 \times($ particle size $\mathrm{n}$ DM intake/particle size $\mathrm{n}$ predicted DM intake). Sorting values equal to $100 \%$ indicate no sorting, $<100 \%$ indicate selective refusals (sorting against), and $>100 \%$ indicate preferential consumption (sorting for). Data are averaged over 3 $\mathrm{d}$ for 6 heifers on each treatment.

${ }^{2}$ Difference in sorting values from $100 \%$ expressed as: $\dagger P<0.15,{ }^{*} P$ $<0.05,{ }^{* *} P<0.01$.

${ }^{3} 2.02 \mathrm{~kg}$ concentrate fed top-dressed on (top dressed) or mixed with (TMR) grass hay fed ad libitum.

${ }^{4}$ Particle size determined by Penn State Particle Separator, which has a 19-mm screen (long), 8-mm screen (medium), 1.18-mm screen (short), and a pan (fine). 

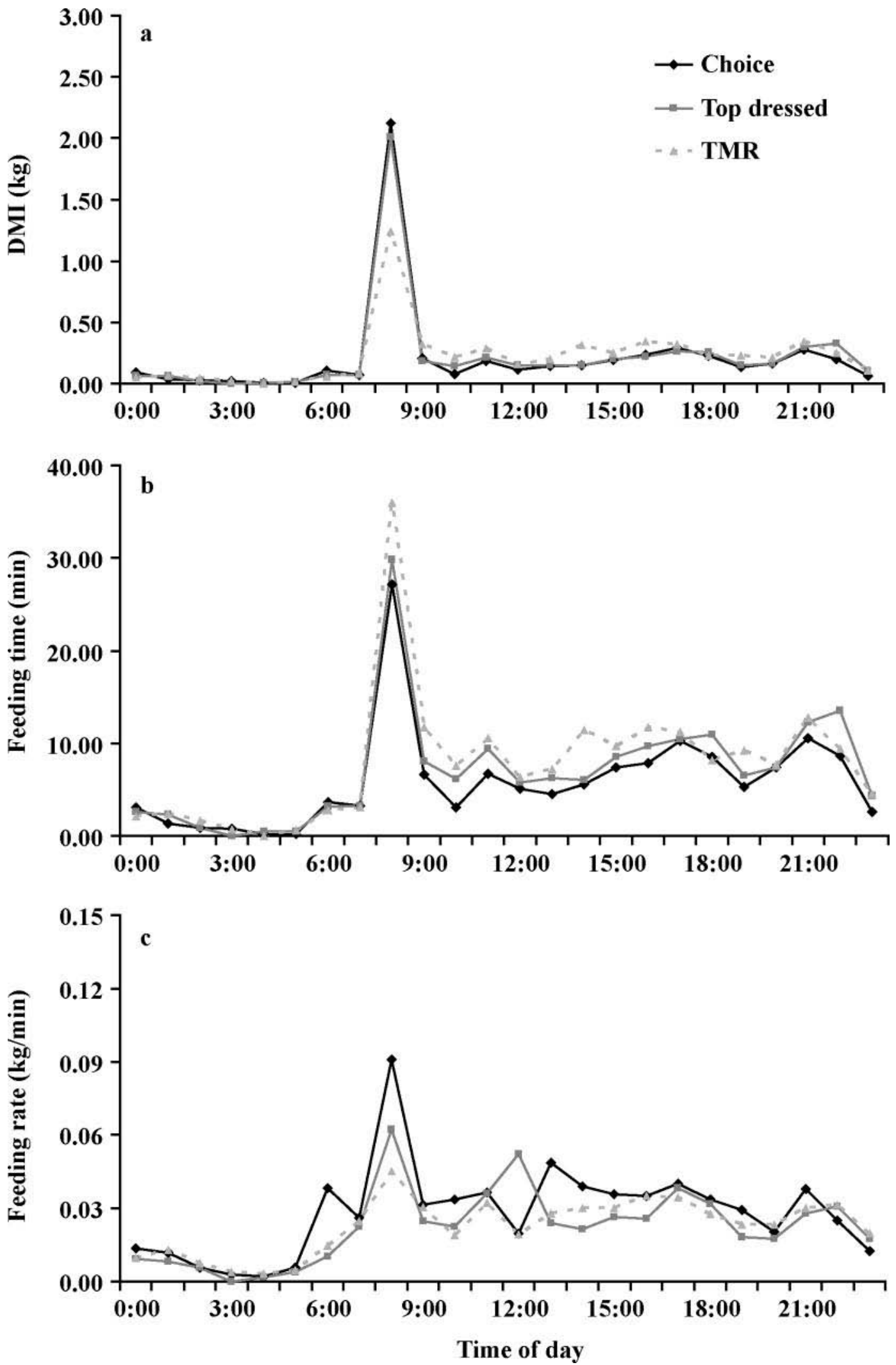

Figure 1. Hourly averages for a) DMI (kg), b) feeding time (min), and c) feeding rate $(\mathrm{kg} / \mathrm{min})$ for growing dairy heifers fed $2.02 \mathrm{~kg}$ concentrate separately from (choice), top-dressed on (top dressed), or mixed with (TMR) grass hay fed ad libitum. Data are averaged over $7 \mathrm{~d}$ for 6 animals on each treatment. 

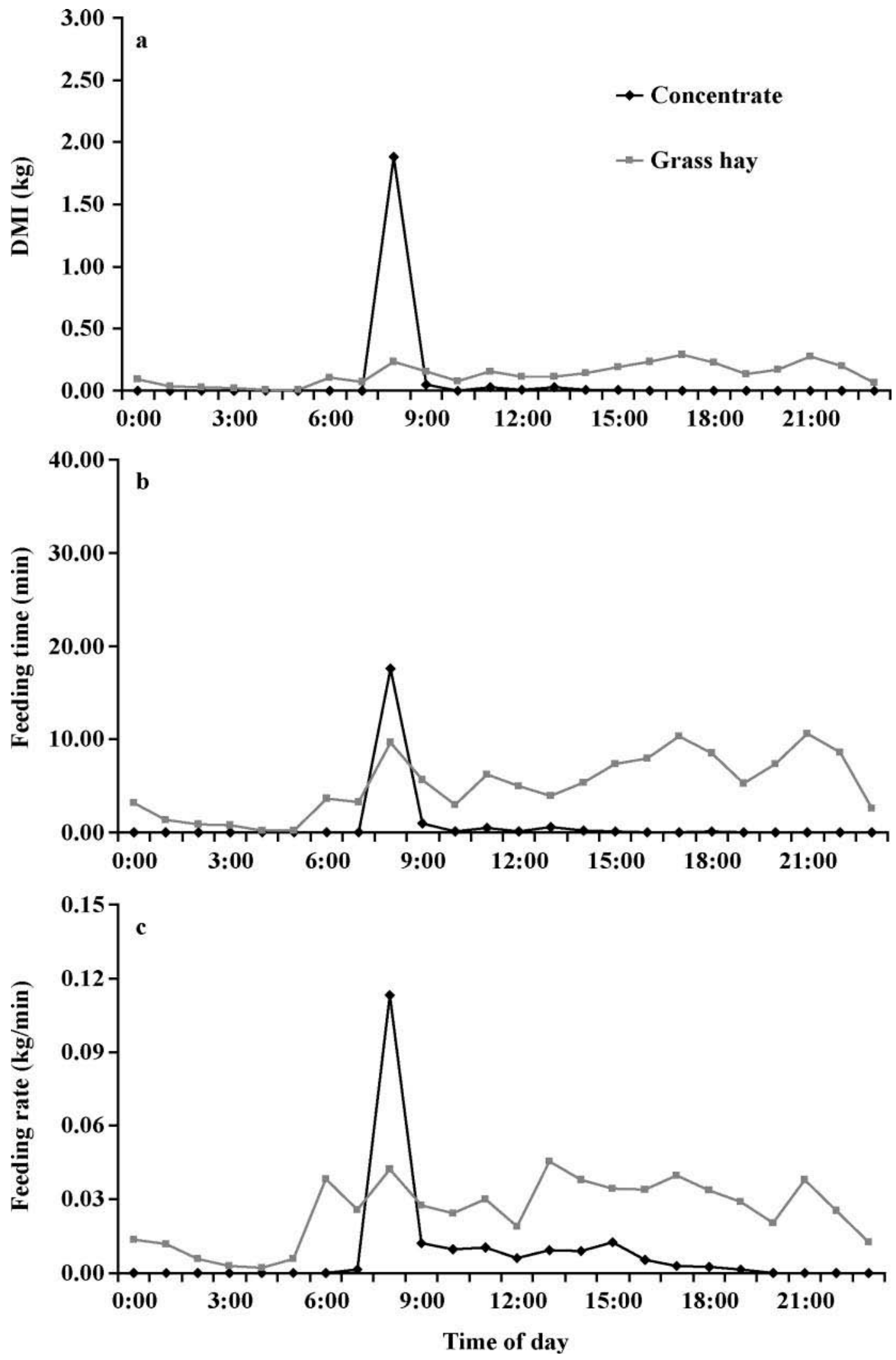

Figure 2. Hourly averages for a) DMI (kg), b) feeding time ( $\min )$, and c) feeding rate $(\mathrm{kg} / \mathrm{min})$ for growing dairy heifers fed the choice of: 1) $2.02 \mathrm{~kg}$ concentrate and 2) ad libitum grass hay. Data are averaged over $7 \mathrm{~d}$ for 6 animals. 
increase in groups of heifers fed concentrate competitively, suggesting disparity between group members as far as their ability to access feed and maintain DMI. Such variability could occur when dominant animals prevent other animals from accessing the feed bunk, thereby enabling them to consume excess DM and reducing the amount of feed available to subordinate animals (Krause and Oetzel, 2006). Further research is needed to validate this, as little is known of how social status and feed bunk competition influence feed access in prepubertal dairy heifers.

Lower feeding times on the choice treatment across the day $(\mathrm{SE}=1.76, P<0.001$; Figure $1 \mathrm{~b})$ reflected the $30 \%$ increase in consumption rate across the day $(\mathrm{SE}=0.008, P=0.004$; Figure 1c) compared with other treatments (Table 2). This higher consumption rate on the choice treatment was largely caused by the dramatically higher rate of intake of the concentrate (0.11 vs. $0.05 \mathrm{~kg}$ of $\mathrm{DM}$ per min; $\mathrm{SE}=0.01, P<0.001$ ). González et al. (2008) also found that feedlot heifers consumed concentrate at a rate greater than $0.1 \mathrm{~kg}$ of DM per min. Our results also concur with reports that component-fed lactating cows consumed concentrate between 3 and 12 times faster than the forage portion of their ration (Beauchemin et al., 2002, 2008). Even though the average rate of DMI of the top-dressed ration was similar to that of the TMR (Table 2), there were differences across the day (Figure 1c). A tendency for a treatment by hour interaction $(P=0.11)$ reflects the higher rate of intake of the top-dressed ration compared with the TMR during the period of peak feeding activity following feed delivery as well as at midday. This provides further evidence that heifers were able to rapidly consume the grain on this treatment. These data are similar to Maekawa et al. (2002), who found that component-fed cows had shorter feeding times and a similar increase in consumption rate compared with TMR-fed cows. Similarly, these researchers also found that component-fed cows ate the concentrate portion more than twice as fast as the forage portion of the ration.

The high concentrate consumption rate raises concern about rumen fermentation patterns given that less saliva is produced per unit of feed consumed for concentrate compared with forages or TMR (Maekawa et al., 2002; Beauchemin et al., 2008). Alternatively, the higher average frequency of small meals by the heifers on the choice treatment (Table 2) would suggest that this feeding method may be beneficial for rumen fermentation patterns. However, when considering the meal data for the concentrate and hay separately, we see that these heifers were consuming their daily concentrate allocation in 2.0 meals/d compared with 9.7 meals $/ \mathrm{d}$ of hay $(\mathrm{SE}=0.6, P<0.001)$. The size of these concentrate meals were also larger (1.28 vs. 0.34 $\mathrm{kg}$ of DM per meal; $\mathrm{SE}=0.13, P=0.002)$. Research with adult cattle has shown that component-fed cows rapidly consume their concentrate in a few, very large meals and, as result, experience more subacute ruminal acidosis than TMR-fed cows (Beauchemin et al., 2002). Given the similarity in feeding behavior results (i.e., increased size of the grain concentrate meals combined with the increased rate of intake of the grain meals) in the present study as compared with those of Beauchemin et al. (2002), we can hypothesize that heifers may experience large postprandial drops in rumen $\mathrm{pH}$ when fed concentrate and forage components separately, and possibly also with top-dressing. This hypothesis is supported by previous research by González et al. (2008) who reported that more than $50 \%$ of feedlot heifers fed concentrate and straw ad libitum experienced moderate acidosis $(\mathrm{pH}<5.6)$. Even though heifers were consuming 2 to 3 times the amount of concentrate as those in the present study, they were consuming a similar amount of NFC per minute of feeding time. This may cause a large postprandial drop in rumen $\mathrm{pH}$, as demonstrated by Quigley et al. (1992) in young growing dairy heifers. Alternatively, the longer feeding times and slower feeding rates observed in heifers consuming the TMR would promote increased daily salivary secretion and, thus, may help prevent low rumen $\mathrm{pH}$ (Beauchemin et al., 2008). As measures of rumen fermentation were not taken in the current study, further research is needed to validate these hypotheses.

Overall, the provision of grain concentrate and hay as a choice resulted in young dairy heifers rapidly consuming the grain concentrate portion of their ration in very few, large meals before consuming the hay portion of their ration. Similar feeding patterns occurred when heifers had their grain concentrate top dressed on the hay, suggesting that this feeding method also facilitated the rapid consumption of grain before consuming hay. Alternatively, providing feed components as a TMR increased the distribution of DMI over the course of the day and reduced the amount of sorting (against long forage particles and for short grain concentrate particles) in young dairy heifers. As result, the provision of a TMR to growing dairy heifers promotes a more balanced intake of nutrients across the day. Further research is needed to fully understand how this influences rumen fermentation patterns in these growing dairy heifers.

\section{ACKNOWLEDGMENTS}

We thank the staff and students at The University of British Columbia's Dairy Education and Research Centre. In particular we thank Angela Greter and Yukiko 
Shima of The University of British Columbia Animal Welfare Program and Audrey Nadalin of Agriculture and Agri-Food Canada for their technical help throughout the data collection period. This project was funded by the Natural Sciences and Engineering Research Council of Canada and the Dairy Farmers of Canada.

\section{REFERENCES}

AOAC. 1990. Official Methods of Analysis. Vol. I. 15th ed. Association of Official Analytical Chemists, Arlington, VA.

AOAC. 2000. Official Methods of Analysis. Vol. I. 17th ed. Association of Official Analytical Chemists, Arlington, VA.

Beauchemin, K. A., L. Eriksen, P. Nørgaard, and L. M. Rode. 2008. Salivary secretion during meals in lactating dairy cattle. J. Dairy Sci. 91:2077-2081.

Beauchemin, K. A., M. Maekawa, and D. A. Christensen. 2002. Effect of diet and parity on meal patterns of lactating dairy cows. Can. J. Anim. Sci. 82:215-223.

Borland, K., and E. M. Kesler. 1979. Complete rations for Holstein calves 8 to 18 weeks of age. J. Dairy Sci. 62:304-309.

Canadian Council on Animal Care. 1993. Guide to the Care and Use of Experimental Animals. Vol. 1. E. D. Olfert, B. M. Cross, and A. A. McWilliam, ed. CCAC, Ottawa, Canada.

Coppock, C. E., D. L. Bath, and B. Harris Jr. 1981. From feeding to feeding systems. J. Dairy Sci. 64:1230-1249.

DeVries, T. J., M. A. G. von Keyserlingk, D. M. Weary, and K. A. Beauchemin. 2003. Measuring the feeding behavior of lactating dairy cows in early to peak lactation. J. Dairy Sci. 86:33543361.

González, L. A., A. Ferret, X. Manteca, J. L. Ruíz-de-la-Torre, S. Calsamiglia, M. Devant, and A. Bach. 2008. Performance, behavior, and welfare of Friesian heifers housed in pens with two, four, and eight individuals per concentrate feeding place. J. Anim. Sci. 86:1446-1458.
Greter, A. M., T. J. DeVries, and M. A. G. von Keyserlingk. 2008 Nutrient intake and feeding behavior of growing dairy heifers: Effects of dietary dilution. J. Dairy Sci. 91:2786-2795.

Hernandez-Urdaneta, A., C. E. Coppock, P. E. McDowell, and D. Gianola. 1976. Changes in forage-concentrate ratio of complete feeds for dairy cows. J. Dairy Sci. 59:695-705.

Kononoff, P. J., A. J. Heinrichs, and D. R. Buckmaster. 2003 Modification of Penn State forage and total mixed ration particle separator and the effects of moisture content on its measurements. J. Dairy Sci. 86:1858-1863.

Krause, K. M., and G. Oetzel. 2006. Understanding and preventing subacute ruminal acidosis in dairy herds: A review. Anim. Feed Sci. Technol. 126:215-236.

Leonardi, C., and L. E. Armentano. 2003. Effect of quantity, quality, and length of alfalfa hay on selective consumption by dairy cows. J. Dairy Sci. 86:557-564.

Maekawa, M., K. A. Beauchemin, and D. A. Christensen. 2002. Effect of concentrate level and feeding management on chewing activities, saliva production, and ruminal $\mathrm{pH}$ of lactating dairy cows. J. Dairy Sci. 85:1165-1175.

Murphy, M. R. 2004. From birth to puberty. Adv. Dairy Tech. $16: 153-160$.

National Research Council. 2001. Nutrient Requirements for Dairy Cattle. 7th rev. ed. Natl. Acad. Sci., Washington, DC.

Østergaard, S., and Y. T. Grohn. 2000. Concentrate feeding, drymatter intake, and metabolic disorders in Danish dairy cows. Livest. Prod. Sci. 65:107-118.

Quigley, J. D., T. M. Steen, and S. I. Boehms. 1992. Postprandial changes in ruminating calves of selected blood and ruminal metabolites fed diets with or without hay. J. Dairy Sci. 75:228235.

SAS Institute. 2003. SAS Users Guide. SAS Inst. Inc., Cary, NC.

Van Soest, P. J., J. B. Robertson, and B. A. Lewis. 1991. Methods for dietary fiber, neutral detergent fiber and non-starch polysaccharide in relation to animal nutrition. J. Dairy Sci. 74:3583-3597. 